\title{
GCC2 is a New Biomarker for Diagnosis of Early Non-Small Cell Lung Cancer and A Potential Target to Reverse Epithelial to Mesenchymal Transition
}

Hyesun Jeong

Korea University - Seoul Campus: Korea University

Byeong Hyeon Choi

Korea University Guro Hospital

Jik-han Jung

Korea advanced institute of science and Technology

Hyunku Shin

Korea university

JinA Park

Korea university

Ka-Won Kang

Korea University Anam Hospital

Yu Hua Quan

Korea University Guro Hospital

Jewon Yu

Exopert incorporation

Ji-Ho Park

KAIST: Korea Advanced Institute of Science and Technology

Yong Park

Korea University Anam Hospital

Yeonho Choi

Korea University - Anam Campus: Korea University

Hyun Koo Kim

Korea University Guro Hospital

Sunghoi Hong ( $\square$ shong21@korea.ac.kr)

Korea University https://orcid.org/0000-0003-4926-1044

\section{Research}

Keywords: Exosomes, non-small cell lung cancer, GCC2, biomarker, therapeutic target 
Posted Date: December 29th, 2020

DOl: https://doi.org/10.21203/rs.3.rs-135611/v1

License: (c) (i) This work is licensed under a Creative Commons Attribution 4.0 International License. Read Full License 


\section{Abstract}

Background. Nano-sized exosomes (30-150 nm) are cell membrane-encapsulated vesicles that contain nucleic acids and proteins. Specific markers detecting non-small cell lung cancer (NSCLC) cell-derived exosomes in the blood circulation remain unidentified. Here, we report a new biomarker distinguishing cancer from non-cancer exosomes that also involved in epithelial to mesenchymal transition for cancer treatment.

Methods. Exosomes were isolated from plasma of patients with various pathological stages of NSCLC and NSCLC cell lines, human pulmonary alveolar epithelial cells by size exclusion chromatography and characterized by Nanoparticle Tracking Analysis and western-blotting. The exosomes were lysed and applied to proteomic analysis. The expression levels of the GCC2 proteins from NSCLC patients were analyzed by ELISA assays, and the effects by GCC2 shRNA were analyzed by real-time RT-PCR, cell migration and colony formation assays.

Results. A protein GRIP and coiled-coil domain-containing 2 (GCC2), which is involved in endosome-toGolgi transport, was identified by the proteomics analysis of exosomes isolated from NSCLC cell lines. The GCC2 protein expression levels were increased in the exosomes derived from patients with earlystage NSCLC compared with healthy controls. The receiver operating characteristic curve of exosomal GCC2 revealed $94.74 \%$ sensitivity and $75.00 \%$ specificity, and AUC of 0.875 . GCC2 knockdown experiments by GCC2 shRNA showed reduced exosome secretion in cancer cell lines, which altered the molecular and cellular properties, such as the expression levels of mesenchymal-to-epithelial genes, and cellular growth and motility.

Conclusion: GCC2 represents a promising biomarker for early diagnosis of NSCLC and a therapeutic target for future cancer treatment.

\section{Background}

Lung cancer is a leading cause of cancer-related death in the world, and non-small cell lung cancer (NSCLC) is the most common typed of lung cancer that accounts for about $85 \%$ of all lung cancer $(1,2)$. NSCLC is further classified into several types, such as adenocarcinoma, squamous cell carcinoma, and large-cell carcinoma. The most common type of lung cancer is adenocarcinoma; it comprises about $40 \%$ of all lung cancer (squamous cell carcinoma; $25 \sim 30 \%$, large cell carcinoma; $5 \sim 10 \%$ of lung cancer) (3). Early stage at diagnosis with screening is linked to better prognosis in lung cancer patients(4). Also, markedly improved survival rates have been reported in patients with early stages of NSCLC who have undergone surgical resection (5-7).

Clinical guidelines recommend annual screening for lung cancer and diagnosis of lung cancer involves multiple methods such as chest X-rays, low-dose computed tomography (LDCT) scan, positron emission tomography (PET-CT), magnetic resonance imaging (MRI), and bronchoscopic- or CT- guided needle biopsy(8). However, these procedures are expensive, difficult for repeating examinations, invasive and 
have a risk of radiation exposure(9). Therefore, low-risk and convenient diagnostic methods are required for early lung cancer diagnosis.

Liquid biopsies captures cancer-related biomarkers in body fluids, such as exosomes, circulating tumor cells (CTCs) or circulating tumor DNA (ctDNA), have great potential as an alternative diagnostic tools for various cancer types $(10,11)$. Unlike CTCs or ctDNA, which are very small in amount per $1 \mathrm{ml}$ of blood and are difficult to detect, exosomes are advantageous for liquid biopsy because they are present in high concentrations and are easy to detect (12). However, diagnosing NSCLC can still be challenging, and new technology to improve diagnostic work-up is required to improve targeted therapies for cancer treatments.

Cells secrete extracellular vesicles, such as exosomes of 30-150 nm in diameter $(13,14)$, which contain nucleic acids and proteins (15). Exosomes are released into the extracellular space and enter the circulation (16). Studies show that exosomes act as modulators of cell-to-cell communication and intracellular biological activity $(17,18)$. Exosomes are cup-shaped structures under the transmission electron microscope. These heterogeneous membrane-enclosed vesicles contain exosome-enriched proteins, including the tetraspanin family (CD63, CD9, and CD81), heat shock proteins (HSP60, HSP70, and HSP90), and members of endosomal sorting complexes required for transport, such as TSG101 and Alix (19). In addition, exosomes can be easily isolated from the cancer patients following a simple blood collection, suggesting that exosomes may be very attractive as a biomarker (20-23). Interestingly, a recent study have identified a GRIP and coiled-coil domain-containing 2 (GCC2)-anaplastic lymphoma kinase (ALK) fusion protein in a patient with NSCLC (24). Overexpression of GCC2-ALK has led to the activation of ALK downstream signaling that is inhibited by ALK inhibitors such as crizotinib and ceritinib, which may allow GCC2 to be directly involved in a promising target for NSCLC diagnosis and/or treatment (25).

In this study, we report a specific biomarker GCC2 distinguishing cancer-specific exosomes from normal cell-derived exosomes derived from body fluids of patients with NSCLC, which may aid in the diagnosis and treatment of cancer. In addition, our GCC2 knockdown experiments directly affected the molecular and cellular alterations of cancer cells, suggesting that GCC2 may be a therapeutic target for cancer prevention.

\section{Materials And Methods}

\section{Patient samples}

Blood samples from human subjects were collected from the Korea University Guro Hospital and Korea University Anam Hospital, Seoul, Korea. The subjects included 16 healthy controls ( 10 male and 6 female; mean age $26.3 \pm 2.4$ years) and 53 patients ( 25 male and 28 female; mean age $65.9 \pm 4.1$ years), who were scheduled to undergo lobectomy with mediastinal lymph node dissection by video-assisted thoracoscopic surgery. The histological type and stage of lung cancer are provided in Table 1. Patients were excluded if they received neoadjuvant chemotherapy before surgery. 
Table 1

Summary of clinical characteristics of patients with non-small cell lung cancer.

\begin{tabular}{|c|c|c|c|}
\hline v & & No. of patients & Percentage (\%) \\
\hline Sex & Male/female & $25 / 28$ & $47.2 / 52.8$ \\
\hline Age & Mean, range & $65.9,48 \sim 80$ & - \\
\hline Histology & Adenocarcinoma & 53 & 100 \\
\hline \multirow[t]{6}{*}{ Site of primary tumor } & Right upper lobe & 16 & 30.2 \\
\hline & Right middle lobe & 6 & 11.3 \\
\hline & Right lower lobe & 15 & 28.3 \\
\hline & Left upper lobe & 8 & 15.1 \\
\hline & Left lower lobe & 7 & 13.2 \\
\hline & Right upper lobe with right lower lobe & 1 & 1.9 \\
\hline \multirow[t]{3}{*}{ Mode of operation } & Lobectomy & 41 & 77.3 \\
\hline & Segmentectomy & 9 & 17.0 \\
\hline & Wedge resection & 3 & 5.7 \\
\hline \multirow[t]{5}{*}{ Invasion } & Lymphatic & 2 & 3.7 \\
\hline & Venous & 3 & 5.7 \\
\hline & Lymphatic with venous & 2 & 3.8 \\
\hline & Lymphatic, venous, and perineural & 1 & 1.9 \\
\hline & None & 45 & 84.9 \\
\hline \multirow[t]{3}{*}{ p-Stage } & T1aN0 - T1bN0 & 19 & 35.8 \\
\hline & T2aNO - T2bNO & 24 & 45.3 \\
\hline & T2aN1, T2bN1, T2aN2, T2bN2 & 10 & 18.9 \\
\hline Tumor size(mm) & Mean, \pm SD & $27.1 \pm 7.1$ & - \\
\hline
\end{tabular}

Peripheral blood samples $(3 \mathrm{ml})$ from healthy controls and patients with lung cancer were collected in EDTA-coated tubes, followed by centrifugation $\left(3,000 \mathrm{rpm}, 4^{\circ} \mathrm{C}, 15 \mathrm{~min}\right)$. The plasma layer was carefully removed without disturbing the buffy coat, transferred to a new tube, and then stored at $-80^{\circ} \mathrm{C}$ until use. A $0.5-\mathrm{ml}$ aliquot of blood plasma was centrifuged $\left(15,000 \times \mathrm{g}, 4^{\circ} \mathrm{C}, 10 \mathrm{~min}\right)$ to remove residual cells, cell debris, apoptotic bodies, and nuclei. The clinical study protocol was approved by the Institutional Review Board of the Korea University Guro Hospital (2014GR0089), and the Institutional Review Board of the Korea University Anam Hospital (2017AN0386). This research was performed in accordance with the 
principles of the Declaration of Helsinki. Informed consent was obtained from all subjects, and all subjects were aged over 18 years.

\section{Exosome isolation from plasma and cell culture medium}

A 0.5-ml aliquot of blood plasma was loaded in a disposable column (10 ml; Thermo Scientific Pierce, Waltham, MA, USA) made of porous Sepharose beads (Sephacryl S-200, Sepharose CL-6B, GE Healthcare Life Sciences, Chicago, IL, USA) in accordance with the commercial protocol. Exosomes were isolated by selecting fractions that coincided with the 30-100-nm size, as measured by nanoparticle tracking analysis (NTA) using a NanoSight NS300 device (Malvern Instruments, Malvern, UK). Each experiment was performed in triplicate (each with a 60-s capture time), and data were analyzed using the NanoSight NTA 2.3 Analytical Software (Malvern Instruments, Malvern, UK).

Human pulmonary alveolar epithelial cells (HPAEpiC) were purchased from ScienCell Research Laboratories and cultured in AEpiCM (ScienCell Research Laboratories, Carlsbad, CA, USA) with growth supplement (EpiCGS), 10\% fetal bovine serum (FBS), and $5 \mathrm{ml}$ penicillin/streptomycin (PE/ST) by following the manufacturer's instructions. NSCLC cell lines A549, PC9, H1299, H522, and H1650 were cultured in RPMI medium (HyClone, Logan, UT, USA) supplemented with 5\% FBS (HyClone, Logan, UT, USA) and 1\% PE/ST (Gibco, Waltham, MA, USA). The FBS used in this experiment was depleted of exosomes by ultracentrifugation $\left(120,000 \times g, 4^{\circ} \mathrm{C}\right)$ for more than $12 \mathrm{~h}$.

In vitro cell culture medium was collected from cells grown to $70 \%$ confluency for $48 \mathrm{~h}$. After sequential centrifugation at $500 \times \mathrm{g}, 4^{\circ} \mathrm{C}$ for $10 \mathrm{~min}$ and $5,000 \times \mathrm{g}, 4^{\circ} \mathrm{C}$ for $30 \mathrm{~min}$ to remove cell debris and intact cells, the supernatant was collected and filtered through a 0.22-um filter and then concentrated using an Amicon ${ }^{\circledR}$ Ultra-100K filter (Merck Millipore, Burlington, MA, USA) according to the manufacturer's protocol. The concentrated supernatant was purified by size exclusion chromatography (SEC) kit (EXoPERT Inc., Seoul, Republic of Korea) and the eluted fractions \#6-8 (0.5 ml each) collected. Aliquots containing exosomes were measured by NTA (Malvern Instruments, Malvern, UK) to determine the particle size.

\section{Transmission electron microscopy (TEM)}

All of the samples were mixed with an equal volume of $4 \%$ paraformaldehyde. Then, $5 \mu$ of the mixed solution was deposited on Formvar-carbon-coated grids and left for 15 min to absorb into the membranes. Next, the grid was transferred to a phosphate-buffered saline droplet for washing and then to a drop of $2.5 \%$ glutaraldehyde for $1 \mathrm{~min}$, followed by washing, with a drop of distilled water, eight times. For contrast samples, the grids were transferred to a drop of phosphotungstic acid solution, $\mathrm{pH} 7$, for $5 \mathrm{~min}$, and the remaining solution was removed using filter paper. After drying, the grids were observed under a transmission electron microscope at $200 \mathrm{kV}$. To prepare the TEM specimen for immunogold labeling, $15 \mu \mathrm{L}$ of the samples was dropped onto the TEM grid. After $10 \mathrm{~min}$, the grid was immersed in PBS droplets three times for washing residual substances. The grid was immersed in $4 \mu \mathrm{g} / \mathrm{mL}$ of antiCD63 antibody solution (Santa Cruz Biotechnology, Dallas, TX, USA) for 2 hrs and washed with PBS droplets. The anti-mouse IgG-gold nanoparticle solution was diluted with PBS (1:20 v/v). The grid was 
immersed in the anti-mouse lgG-gold nanoparticles solution for $1 \mathrm{hr}$ and washed with PBS, and then fixed by $2.5 \%$ glutaraldehyde and washed with a drop of distilled water. The residual solution was removed by a paper wipe and the grid was thoroughly dried.

\section{Western blotting}

The protein of cultured cells and exosomes were harvested using the radioimmunoprecipitation assay buffer (Thermo Scientific, Waltham, MA, USA) with the addition of Halt ${ }^{\text {tM }}$ Protease Inhibitor Cocktail (Thermo Scientific, Waltham, MA, USA). Lysates were centrifuged $\left(15,000 \mathrm{rpm}, 4^{\circ} \mathrm{C}\right)$ for $10 \mathrm{~min}$, and the supernatant was collected in a new tube.

The protein concentration was measured by the Bradford assay, and the appropriate amount of each sample was boiled with 5X SDS-PAGE sample buffer (Thermo Scientific, Waltham, MA, USA). The samples were separated on a $6 \%$ and $12 \%$ SDS acrylamide gel and transferred to a PVDF membrane. The membrane was blocked in 5\% skimmed milk in TBST with $0.1 \%$ Tween 20 for $1 \mathrm{~h}$, then incubated with CD63 (SC-15363, Santa Cruz Biotechnology, Dallas, TX, USA), CD9 (SC-13118, Santa Cruz Biotechnology, Dallas, TX, USA), CD81 (bs-6943R, Bioss, Woburn, MA, USA), CD31 (SC-376764, Santa Cruz Biotechnology, Dallas, TX, USA) and GCC2 (SC-242898, Santa Cruz Biotechnology, Dallas, TX, USA), primary antibodies, followed by incubation with horseradish peroxidase-conjugated secondary antibodies used at a dilution of 1:10,000.

Establishment of green fluorescent protein (GFP)-positive (+) cell lines under the control of CD63 promoter and GCC2 knockdown

pCMV6-CD63-GFP vector was purchased from OriGene Technologies, Inc. H1299, H522, and HPAEpiC were grown overnight in a $60-\mathrm{mm}$ dish to $60-70 \%$ confluence, then transfected with $2.5 \mu \mathrm{g} / \mathrm{dish}$ of purified pCMV6-CD63-GFP by using Lipofectamine 2000 (Invitrogen, Waltham, MA, USA) according to the manufacturer's protocol. Cells were selected in appropriate growth medium containing $500 \mu \mathrm{g} / \mathrm{mL}$ geneticin (G418) for 3 weeks. G418-resistant and GFP + cells were isolated by fluorescence-activated cell sorting using a FACSAria, then expanded and maintained by cell culture in selection medium at low density (100 $\mu \mathrm{g} / \mathrm{mL})$. To perform GCC2 knockdown, the GCC2 shRNA vector (Dharmacon, Lafayette, CO, USA) was transfected to the NSCLC cell lines using Lipofectamine 2000 (Invitrogen, Waltham, MA, USA) by following the manufacturer's protocol.

\section{Proteomics analysis}

The exosome lysates were fractionated on 4-12\% SDS-PAGE. Afterward, the gels were diced into $<1 \mathrm{~mm}^{2}$ pieces and rinsed with $200 \mu \mathrm{l}$ of water, then twice with $200 \mu \mathrm{l}$ of $25 \mathrm{mM}$ ammonium bicarbonate in $50 \%$ acetonitrile, followed by $100 \mu \mathrm{l}$ acetonitrile to dehydrate the gel plugs, which were then lyophilized. The dry gel plugs were rehydrated in $150 \mu \mathrm{l}$ of $25 \mathrm{mM}$ ammonium bicarbonate ( $\mathrm{pH}$, with $12.5 \mathrm{ng} / \mu \mathrm{l}$ trypsin). After rehydration, the gel plugs were incubated overnight at $37^{\circ} \mathrm{C}$ in ammonium bicarbonate $(100 \mu \mathrm{l}$, $25 \mathrm{mM}$ ). Digested samples were desalted using a $\mathrm{C}_{18}$ micro spin column (Harvard Apparatus, Cambridge, MA, USA). The pooled extracts were reduced to dryness and reconstituted in $80 \%$ acetonitrile $/ 0.1 \%$ formic 
acid for trapped ion mobility spectrometry coupled to time-of-flight mass spectrometry (timsTOF MS). Samples were analyzed on a nanoElute (Bruker, Billerica, MA, USA) coupled to a timsTOF Pro (Bruker, Billerica, MA, USA) equipped with a CaptiveSpray source. Peptides were separated on a $25 \mathrm{~cm} \times 75 \mu \mathrm{m}$ analytical column (1.6- $\mu \mathrm{m} \mathrm{C}_{18}$ beads packed into an emitter tip; lonOpticks, Victoria, Australia) with a linear gradient of $2-95 \%$ of solvent B (100\% acetonitrile/ $0.1 \%$ formic acid) over a 120 -min gradient at a constant flow $(0.4 \mu \mathrm{l} / \mathrm{min})$. The column was maintained at $50^{\circ} \mathrm{C}$. The timsTOF Pro was operated in PASEF mode using Compass HyStar 5.0.37.1. Six samples were analyzed per day with the following settings: mass range $100-1700 \mathrm{~m} / \mathrm{z}, 1 / \mathrm{K}_{0} 0.6-1.3 \mathrm{~V} \Downarrow \mathrm{s} / \mathrm{cm}^{2}$, ramp time $100 \mathrm{~ms}$, lock duty cycle to $100 \%$, capillary voltage $1600 \mathrm{~V}$, dry gas $3.0 \mathrm{l} / \mathrm{min}$, dry temperature $180^{\circ} \mathrm{C}$; PASEF settings: $10 \mathrm{MS} / \mathrm{MS}$ scans (total cycle time $1.16 \mathrm{~s}$ ), charge range $0-5$, an active exclusion for $0.4 \mathrm{~min}$, scheduling target intensity 20,000, intensity threshold 2500, CID collision energy $10 \mathrm{eV}$.

Data files were uploaded to PEAKS X (Bioinformatics Solutions, Waterloo, Canada) for de novo sequencing and database searching. The sequences were searched against the UniProt database (downloaded 2019-1; 34,064 entries). We searched with mass error tolerances of $20 \mathrm{ppm}$ and 0.05 Da for parent and fragment ions, respectively. Trypsin enzyme specificity and acetylation (protein N-terminal), methionine oxidation, and phosphorylation (STY) were set as variable modifications. False discovery rate (FDR) estimation was enabled. Peptides were filtered at a 1\% FDR at the peptide-spectrum match level, and protein filtering was disabled by setting the protein - $\log 10[\mathrm{P}]$ score at two unique peptides with a requirement for significant peptides.

\section{Quantitative real-time PCR (qRT-PCR)}

Total RNA was extracted with TRI reagent (Invitrogen, Waltham, MA, USA) by following the manufacturer's instructions. cDNA was synthesized using $5 \mu \mathrm{g}$ of total RNA by reverse transcriptase (Roche, Basel, Switzerland) and oligo dT primers. qRT-PCR was performed in triplicate with KAPA SYBR FAST ABI Prism qPCR kit reagents (KAPA Biosystems, Burlington, MA, USA). The primers for the genes of interest were synthesized by Cosmogenetech (Seoul, Republic of Korea) (Supplementary Table S1).

\section{Enzyme-linked immunosorbent assay (ELISA) for exosomal GCC2 detection}

A GCC2 ELISA assay was performed using the GCC2 ELISA kit (MyBioSource, San Diego, CA, USA) according to the manufacturer's instructions.

\section{In vitro scratch assay}

H1299 cells transfected with GCC2 shRNA plasmid DNAs were cultured for $24 \mathrm{~h}$ to achieve $100 \%$ confluence. A scratch was made in the cell monolayer using a $200-\mu l$ sterile pipette tip. Cells were then incubated with fresh media for different times $(0,6,24 \mathrm{~h})$ at $37^{\circ} \mathrm{C}$ in a $5 \% \mathrm{CO}_{2}$ incubator. The scratch gap width was measured at three different positions and compared with the gap width at $0 \mathrm{~h}$ (26).

\section{Colony formation assay}


H1299 cells transfected with GCC2 shRNA plasmid DNAs were seeded into six-well plates at a density of 1,000 cells/well. Cells were incubated for 10 days, then fixed with methanol and stained with $0.2-0.3 \%$ crystal violet for $10 \min (27)$.

\section{Transwell migration and invasion assay}

Cell migration and invasion assays were performed using a Transwell chamber (Corning Inc., Corning, NY, USA, 8- $\mu \mathrm{m}$ pore) according to the manufacturer's instructions (28). The transwells were coated by collagen $\left(10 \mu \mathrm{g} / \mathrm{ml}\right.$ in $\left.\mathrm{H}_{2} \mathrm{O}\right)$ for the migration assay. Cells were seeded in the upper chamber at 3,000 cells in $200 \mu \mathrm{l}$ of serum-free medium and bottom wells were filled with complete medium. After $24 \mathrm{~h}$, cells were stained with crystal violet (0.2-0.3\%) and measured by ImageJ software (Rasband WS, ImageJ, US National Institutes of Health, Bethesda, MD, USA) to obtain an average cell number. For the cell invasion assay, the transwells were coated by Matrigel (BD Biosciences, Franklin Lakes, NJ, USA), and the experimental procedures were the same as the cell migration assays.

\section{Statistical analysis}

Differences in exosomal GCC2 concentration between groups were assessed using one-way ANOVA, followed by the Scheffe or $t$-test. Kruskal-Wallis and Jonckheere-Terpstra tests were used to evaluate the tendency of exosomal GCC2 concentrations at different pathological stages. Statistical analysis was performed using IBS SPSS Statistics 22.0 (IBM Corp., Armonk, NY, USA) and MedCalc 19.0.3 (MedCalc Software, Mariakerke, Ostend, Belgium), and with consultation from the Medical Statistical Consulting Center of the Korea University Guro Hospital. Bar graphs were generated using GraphPad Prism 7 (GraphPad Software, San Diego, CA, USA). Data are expressed as mean \pm SD.

\section{Results}

\section{Isolation of exosomes by SEC}

High-quality exosome purification is crucial for basic research and applications, such as the diagnostics of various diseases using exosomes. Exosomes were isolated from precleared cell culture media and plasma samples by centrifugation and SEC, as reported in our previous studies (29-31). NTA was performed to determine the size and concentration of exosomes in the eluted fractions. Fractions that contained vesicles of similar size to exosomes (30-150 nm) and abundant concentration were pooled and used as an exosome solution.

NTA showed the concentrations and size distribution profiles of the pooled exosome-rich fractions, which mostly lay within the 30-150 nm size range of exosomes (Fig. 1(a,d)). The exosomes were shown to be immunoreactive to the exosome-specific markers CD63, CD9 and CD81 by western blotting (Fig. 1(b,e)), and they exhibited a typical exosome-like cup-shaped morphology with a diameter of about $100 \mathrm{~nm}$ when examined by TEM (Fig. 1(c,f)). The exosomes derived from HPAEpiC and plasma of healthy control were positive against an anti-CD63 antibody with gold nanoparticle tagged secondary antibody by TEM analysis (Fig. 1(g)). 
The exosomal particles $(10 \mu \mathrm{g})$ isolated by our SEC system were lysed and loaded on SDS-PAGE gel, as shown in our previous studies $(31,32)$. The markers CD63 and CD9 were distinctly detected in the exosomal proteins derived from the NSCLC cell lines compared with HPAEpiC, but CD9 was more expressed than CD81 in the overall lung cell lines (Fig. 1(b)). Taken together, we established a high-quality exosome purification method, which showed exosome sizes ranging from 30 to $150 \mathrm{~nm}$.

Identification of GCC2 as a potential marker for NSCLC diagnosis from a variety of lung cancer cell lines

We analyzed the exosomes from the cell lines (HPAEpiC, H1299, H522, A549, PC9, H1650). To identify the NSCLC exosomal markers, we selected the cancer cell lines containing mutations in KRAS, EGFR, and tumor protein p53 (TP53). $\mathrm{H} 1299$ has neuroblastoma RAS (NRAS) mutant, H522 has TP53 mutant, A549 has KRAS mutant, and PC9 and $\mathrm{H} 1650$ have EGFR mutant. The normal epithelial cell line originated from human pulmonary alveolar epithelial cell (HPAEpiC) served as the control cells. The protein composition of exosomes isolated from the cell lines (HPAEpiC, H1299, H522, A549, PC9, H1650) was determined by proteomics analysis. The number of abundant exosomal proteins totaled 165 in HPAEpiC, 231 in H1299, 436 in H522, 338 in PC9, 214 in A549, and 258 in H1650 (Supplementary Table S2). To identify the exosomal proteins derived from the lung cancer cell lines compared with normal HPAEpiC, the exosomal proteins from each cell line were grouped (Fig. 2(a)). Five proteins, namely TUBA1C, GAPDH, KRT25, GCC2, and POTEKP, were identified as potential lung cancer-specific exosome biomarkers. These proteins were annotated with gene ontology (GO) terms using PANTHER (http://www.pantherdb.org). Most of them are involved in cellular processes and cellular component organization or biogenesis.

We selected the protein GCC2, which is a trans-Golgi network (TGN) membrane protein that functions as a tether for vesicles containing mannose 6-phosphate receptors inbound from late endosomes to the TGN (33). According to the Human Protein Atlas, GCC2 can be used as a prognostic marker in liver cancer, albeit with low confidence, currently (http://www.proteinatlas.org). To examine whether GCC2 protein could be used as a potential marker of lung cancer, we tested the RNA and protein expression levels in the cell lines. The qRT-PCR analysis showed a four-fold higher expression of the GCC2 gene in H1299 and H522 compared with HPAEpiC and the other cancer cell lines, which suggests that GCC2 expression is likely to be a unique character in the specific cell types of lung cancer (Supplementary Figure $\mathbf{S 1}(\mathrm{a}))$.

Next, to examine whether the GCC2 protein is expressed in the cancer cell line-derived exosomes, we analyzed the GCC2 protein levels in the exosome lysates of H1299, H522, and HPAEpiC cells. The GCC2 protein was expressed in the exosome lysates of $\mathrm{H} 1299$ and $\mathrm{H} 522$ but barely expressed in the HPAEpiC (Fig. 2(b)). Interestingly, when we compared the number of exosomes per cell between HPAEpiC and cancer cell lines, more exosomes were secreted by the cancer cell lines (Supplementary Figure S1(b)). In addition, we found that the exosome concentration in plasma derived from the patients with lung cancer increased progressively as pathological stages increased (Supplementary Figure S1(c)). Moreover, to examine whether the GCC2 protein is present or absent on the surface of the exosomes, we performed western blot experiments. When the exosomal lysates derived from the patients with lung cancer were 
digested with proteinase K, the GCC2 protein was completely degraded compared with no proteinase $\mathrm{K}$ treatment, as shown in lanes 1 and 2 of Fig. 2(c). A membrane protein CD31 was used as a control. Furthermore, when the exosomal lysates were treated with the detergent TritonX-100 (lanes 3 and 4), the GCC2 protein levels increased noticeably compared with the untreated sample (lane 1). Collectively, these results indicate that the increased number of exosomes with GCC2 secreted as a cell-surface protein could be a predictive marker for lung cancer diagnosis, suggesting that GCC2 could be a potential biomarker for NSCLC.

Verification of GCC2 as a specific biomarker for early lung cancer diagnosis in patients with NSCLC We first performed western blot analysis of the exosomes isolated from patients with lung cancer $(N=53)$ diagnosed with NSCLC adenocarcinoma stage T1aN0-T1bNO ( $=19,41.3 \%), T 2 a N 0-T 2 b N 0(N=24$, $52.17 \%)$, and $\mathrm{T} 2 \mathrm{aN} 1-\mathrm{T} 2 \mathrm{bN} 1-\mathrm{T} 2 \mathrm{aN} 2-\mathrm{T} 2 \mathrm{bN} 2(\mathrm{~N}=10,6.5 \%)$, and normal controls $(\mathrm{N}=16)$ without a cancer diagnosis (Table 1). GCC2 expression was very weak in the normal group but gradually increased in the patients as the pathological stages of lung cancer progressed (Fig. 3(a)). The exosomal markers CD63 and $C D 9$ were used to standardize the GCC2 expression levels at the different pathological stages. Surprisingly, the expression levels of GCC2 protein increased by more than 2.8 -fold $(p<0.0001)$ in patients with early-stage lung cancer (T1aN0-T1bN0) compared with the normal group. However, the expression levels of the CD63 and CD9 proteins were not increased significantly compared with those of GCC2 (Fig. 3(b)).

Supplementary Figure S2 shows the GCC2 expression levels between the normal group and the different pathological stages of the patient groups. The relative intensity value was 5.5 -fold $(p<0.000)$ in T2aNOT2bN0 and 7.3-fold $(p<0.000)$ in T2aN1-T2bN1-T2aN2-T2bN2, respectively. However, the relative intensities of CD63 and CD9 were increased by 2.9-fold $(p<0.0001)$ and 2.0-fold $(p>0.05)$ in T2aNOT2bN0, and 3.8-fold $(p=0.004)$ and 3.3-fold $(p<0.0001)$ in T2aN1-T2bN1-T2aN2-T2bN2, respectively. According to the progress of the pathological stage, the most significant $p$-value corresponds to CD63 (trend test $p$-value $<0.0001$ vs. CD9 trend test $p$-value $<0.001$ ).

Thus, to precisely examine the expression levels of GCC2 protein, we counted the same number of exosome particles to $1.0 \times 10^{9}$ particles/ml by NTA at all the pathological stages, followed by western blot. As shown in Fig. 3(c,d), the expression levels of GCC2 but not CD63 increased gradually as the pathological stages progressed.

Next, we quantitated the expression levels of the exosomal GCC2 protein in plasma from patients with early-stage lung cancer by an ELISA assay. Results (Fig. 4(a)) showed the concentration of GCC2 protein was significantly high (normal $40.1 \mathrm{pg} / \mathrm{ml}$ vs. patients $88.3 \mathrm{pg} / \mathrm{ml}, p<0.0001$ ) in patients with early-stage lung cancer (T1aN0-T1bNO; $n=19)$ compared with the normal controls $(n=16)$. When the GCC2 protein concentration was compared between normal controls and patients with different pathological stages of lung cancer, it was increased by 3.8 -fold (normal $40.1 \mathrm{pg} / \mathrm{ml}$ vs. patients $152.5 \mathrm{pg} / \mathrm{ml}, p<0.0001$ ) in 
middle-stage T2aN0-T2bN0 and 5.6-fold (normal $40.1 \mathrm{pg} / \mathrm{ml}$ vs. patients $497.4 \mathrm{pg} / \mathrm{ml}, p<0.0001$ ) in latestage T2aN1-T2bN1-T2aN2-T2bN2 (Supplementary Figure S3(a,c)).

We subsequently constructed a receiver operating characteristic (ROC) curve to assess the diagnostic value of the exosomal GCC2 protein for patients with early-stage lung cancer. The sensitivity and specificity values of exosomal GCC2 were $94.74 \%$ and $75 \%$, respectively, with an AUC of 0.875 (95\% confidence interval [Cl]: $0.82-0.96, p<0.0001$ ), and a cut-off of $12.3 \mathrm{pg} / \mathrm{ml}$ (Fig. $4(\mathrm{~b})$ ). In the patient groups at different pathological stages, the sensitivity and specificity values of exosomal GCC2 were $75.00 \%$ and $81.25 \%$, respectively, with an AUC of 0.823 (95\% Cl: $0.82-0.96, p<0.0001$ ) at T2aNO-T2bNO, and $90.00 \%$ and $87.50 \%$, respectively, with an AUC of 0.906 (95\% Cl: $0.82-0.96, p<0.0001)$ at late-stage T2aN1-T2bN1-T2aN2-T2bN2 (Supplementary Figure S3(b,d)).

These results show that the expression levels of GCC2 protein were robustly high in a group of patients with lung cancer compared to the normal group. Notably, the GCC2 expression levels were significantly high in patients with early-stage (T1aN0-T1bN0) lung cancer, which suggests that GCC2 protein could be a feasible, valuable, and non-invasive biomarker for early diagnosis of lung cancer using lung cancer blood-derived exosomes.

\section{Potentials of GCC2 as an effective target for cancer treatment by GCC2 knockdown}

Given that the GCC2 protein plays an important role in exosome biogenesis and secretion (34), we purchased a lentiviral vector containing a GCC2 shRNA. To monitor the cell secretion of the exosomes, we transfected a CD63-GFP plasmid DNA containing GFP as a reporter under the control of CD63 promoter into HPAEpiC, H1299, and H522 by Lipofectamine 2000 (Supplementary Figure S4(a)). A GFP + stable cell line was selected by antibiotics G418, and sorted by FACS (Supplementary Figure S4(b,c)).

To examine the amounts of secreted exosomes in the GFP + stable cell line, we performed GCC2 knockdown (GCC2-KD) using the GCC2 shRNA lentiviral vector. qRT-PCR and western blotting analyses (Fig. 5(a,b)) showed the gene and protein expression levels of GCC2 were decreased. First, our NTA analysis determined that the number of secreted exosomes was dramatically decreased in GCC2-KD H1299 cells compared with control cells (Fig. 5(c)). Interestingly, we observed that the GCC2-KD cells tightly adhered to each other via membrane-membrane interactions, but not in control cells that are not GCC2-KD cells (Fig. 5(d)). These results show that GCC2 can directly influence the exosome secretion from cancer cells and the cellular morphology, suggesting that GCC2-KD may affect other cancer cell behaviors, such as the expression levels of MET genes, cell migration, and the tumorigenicity in cancer cells.

With the consideration that the exosomes secreted from cancer cells may be a key factor contributing to tumor stimulation $(35,36)$, the regulation of the exosomes released from the cancer cells could be a feasible strategy to develop an effective target for cancer treatments. To examine whether GCC2-KD can directly affect the molecular and cellular alterations of cancer cells, we first analyzed the expression 
levels of mesenchymal-epithelial transition (MET) genes by real-time RT-PCR. We found that the mesenchymal cell marker genes, such as N-cadherin, Slug, Snail, Twist1, and Zeb1, were decreased significantly in GCC2-KD H1299 cells compared with a control cell line in which GCC2 is not knocked down, while the expression levels of E-cadherin gene as an epithelial cell marker showed no significant change (Fig. 5(e)). These results show that GCC2-KD can contribute to altering the molecular properties of lung cancer cells.

In addition, when we compared the cellular motility between H1299 and GCC2-KD H1299 cell lines, the cellular motility was dramatically suppressed in GCC2-KD H1299 cells (Fig. 5(f)). In our colony assay, the colony-forming ability was decreased significantly in the GCC2-KD H1299 cells compared with H1299 cells (Fig. 5(g)). Moreover, we compared the cell migration and invasion abilities in the GCC2-KD H1299 cell lines, which were decreased significantly compared with control cells (Fig. 5(h)). These results show that knocking down GCC2 can inhibit the cellular motility and tumorigenicity of cancer cells, suggesting that GCC2 may be an effective target for the prevention of cancer cell growth and metastasis.

\section{Discussion}

Considering that the detection of early-stage NSCLC could reduce the relapse and mortality $(37,38)$, a new early diagnostic biomarker could be a prerequisite for NSCLC treatment. Currently, surgical resection of tumors is possible in only around $20 \%$ of patients with NSCLC owing to late diagnosis (39). Recent studies have suggested the diagnostic potential of exosomal proteins for NSCLC $(40,41)$. Several invaluable advantages for exosomes as biomarkers are their easy acquisition, isolation, and storage.

Here, we isolated and characterized the exosomes from normal and cancer cell lines, as well as from the plasma of healthy individuals and patients with different pathological stages of NSCLC. The number and size distributions of exosomes were quantified by western blot and TEM analysis (Fig. 1). Interestingly, the number (Supplementary Figure S1(c)) but not the average size of the secreted exosomes (Supplementary Table S3) was significantly different between normal healthy individuals and the patients with early-stage lung cancer. These results suggest that a numerical increase in the exosomes from plasma of patients with cancer could be a potential marker for cancer diagnosis.

We identified a potential exosomal protein GCC2 by proteomic analysis of the exosomal proteins extracted from five cancer cell lines (Fig. 2). GCC2 is a peripheral membrane protein localized to the TGN that interacts with many other proteins and has diverse functions $(33,42,43)$. GCC2 is expressed by most cancer cell types but displays relatively moderate cytoplasmic and membranous immunoreactivity in most cancers, including lung cancer (44).

Interestingly, the GCC2 protein level increased dramatically in exosomes isolated from the cancer cell lines and the plasma of patients with different pathological stages of NSCLC compared with the respective controls (Fig. 2(b) and Fig. 3). In particular, the GCC2 protein level increased progressively in the patients as the pathological stages of lung cancer progressed compared with the normal group (Supplementary Figure S2), indicating that GCC2 + exosomes could be a reliable biomarker for detection 
of NSCLC. These results suggest that that the NSCLC-derived exosomes are enriched with GCC2 protein, and the GCC2 + exosomes could be a prognostic and safe marker because computed tomography would be risky and expensive to patients requiring several exposures.

Surprisingly, the GCC2 protein was significantly high in the plasma of patients with early-stage (T1aNOT1bN0) NSCLC (Fig. 3(a,b)). We also evaluated the diagnostic capacity of the exosomal GCC2 protein in patients with early-stage lung cancer. The exosomal GCC2 displayed a sensitivity of $94.74 \%$ and a specificity of $75.00 \%$, although the accuracy was relatively higher in patients with the more advanced pathological stages (Supplementary Figure S3(d)). Our ROC curve analysis showed that GCC2 has a diagnostic potential with AUC of 0.875 (95\% Cl: 0.82-0.96, $p<0.0001)$ when comparing healthy individuals and patients with early-stage NSCLC. These results suggest that the use of GCC2 as a biomarker may provide accurate information for detecting early-stage NSCLC. Recently, we reported that early-stage lung cancer could be diagnosed through deep-learning-based surfaced-enhanced Raman spectroscopy analysis of the circulating exosomes (30).

Furthermore, our knockdown experiments of the GCC2 protein decreased the secretion of exosomal particles in cancer cell lines dramatically based on NTA analysis (Fig. 5(c)). Although the reduction mechanisms of exosome secretion are not exactly identified, they could affect multiple cellular behaviors, such as gene expression, cell morphology, cell proliferation, and cell motility, as shown in the cancer cell lines (Fig. 5(d-h)). These results suggest that GCC2 may be a therapeutic target for the prevention of cancer cell growth and motility. However, studies remain on the role of GCC2 itself and its downstream targets or signaling pathways, which may influence the cellular behaviors such as EMT, cell migration and invasion in lung cancer cells.

In conclusion, our results provide evidence of GCC2 as an exosomal biomarker for the diagnosis of early NSCLC. The sensitivity and specificity values of exosomal GCC2 were significantly high, and GCC2 shows a promising AUC value (0.875) for discriminating between patients with early NSCLC from healthy controls in our ROC curve analysis. In addition, knocking down GCC2 protein significantly reduced the amount of exosome secretion, which may affect the expression levels of MET genes, alter the cellular morphology, and inhibit the colony-forming abilities and the cellular motility, including the invasion and migration potentials, in the cancer cell lines. These results suggest that GCC2 protein may be a new promising biomarker for diagnosis of early NSCLC, and may also be a therapeutic target for cancer treatment in the future.

\section{Declarations}

\section{Ethics approval and consent to participate}

The clinical study protocol was approved by the Institutional Review Board of the Korea University Guro Hospital (2014GR0089), and the Institutional Review Board of the Korea University Anam Hospital (2017AN0386). This research was performed in accordance with the principles of the Declaration of Helsinki. Informed consent was obtained from all subjects, and all subjects were aged over 18 years. 


\section{Consent for publication}

Not applicable.

\section{Availability of data and materials}

The datasets used and/or analysed during the current study are available from the corresponding author on reasonable request.

\section{Competing interests}

The authors declare that they have no competing interests.

\section{Funding}

This work was supported by grants from the Ministry of Health \& Welfare (HR14C0007), and the Ministry of Science and ICT (2019M3E5D5065399) of the Government of the Republic of Korea.

\section{Authors' contributions}

SH and HKK: conception and design, data analysis and interpretation, manuscript writing, final approval of manuscript. $\mathrm{HJ}$ and BHC: conception and design, collection and/or assembly of data, data analysis and interpretation, manuscript writing; KK, YHQ: ethical authorizations, collection and assembly of patient data. JJ, HS, JAP, JY: isolation of exosomes and collection of exosome analysis data. JHP, YP, YC: the interpretation of the data. All authors read and approved the final manuscript.

\section{Acknowledgements}

Not applicable.

\section{References}

1. Spira A, Ettinger DS. Multidisciplinary Management of Lung Cancer. N Engl J Med. 2004;350(4):37992.

2. Siegel RL, Miller KD, Jemal A. Cancer statistics. 2019. CA: A Cancer Journal for Clinicians. 2019;69(1):7-34.

3. Zappa C, Mousa SAJTIcr. Non-small cell lung cancer: current treatment and future advances. 2016;5(3):288.

4. GOEBEL C, LOUDEN CL, MCKENNA R, ONUGHA O. WACHTEL A, LONG T. Diagnosis of Non-small Cell Lung Cancer for Early Stage Asymptomatic Patients. Cancer Genomics-Proteomics. 2019;16(4):22944.

5. Party IW. Guidelines on the selection of patients with lung cancer for surgery. Thorax. 2001;56:89108. 
6. Raman V, Yang C-FJ, Deng JZ, D'Amico TA. Surgical treatment for early stage non-small cell lung cancer. Journal of thoracic disease. 2018;10(Suppl 7):898.

7. Rosen JE, Keshava HB, Yao X, Kim AW, Detterbeck FC, Boffa DJ. The natural history of operable nonsmall cell lung cancer in the National Cancer Database. Ann Thorac Surg. 2016;101(5):1850-5.

8. Reck M, Rabe KF. Precision diagnosis and treatment for advanced non-small-cell lung cancer. N Engl J Med. 2017;377(9):849-61.

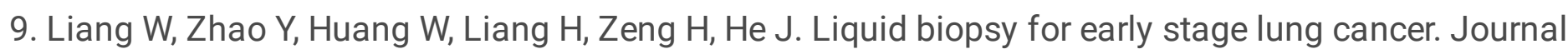
of thoracic disease. 2018;10(Suppl 7):876.

10. Bardelli A, Pantel K. Liquid biopsies, what we do not know (yet). Cancer cell. 2017;31(2):172-9.

11. Palmirotta R, Lovero D, Cafforio P, Felici C, Mannavola F, Pellè E, et al. Liquid biopsy of cancer: a multimodal diagnostic tool in clinical oncology. Therapeutic advances in medical oncology. 2018;10:1758835918794630.

12. Zhang W, Xia W, Lv Z, Xin Y, Ni C, Yang L. Liquid biopsy for cancer: circulating tumor cells, circulating free DNA or exosomes? Cell Physiol Biochem. 2017;41(2):755-68.

13. Pan BT, Teng K, Wu C, Adam M, Johnstone RM. Electron-Microscopic Evidence for Externalization of the Transferrin Receptor in Vesicular Form in Sheep Reticulocytes. J Cell Biol. 1985;101(3):942-8.

14. Kalluri R, LeBleu VS. The biology, function, and biomedical applications of exosomes. Science. 2020;367(6478).

15. Trajkovic K, Hsu C, Chiantia S, Rajendran L, Wenzel D, Wieland F, et al. Ceramide triggers budding of exosome vesicles into multivesicular Endosomes. Science. 2008;319(5867):1244-7.

16. Ostrowski M, Carmo NB, Krumeich S, Fanget I, Raposo G, Savina A, et al. Rab27a and Rab27b control different steps of the exosome secretion pathway. Nature cell biology. 2010;12(1):19-30; sup pp 113.

17. Zhao H, Yang L, Baddour J, Achreja A, Bernard V, Moss T, et al. Tumor microenvironment derived exosomes pleiotropically modulate cancer cell metabolism. eLife. 2016;5:e10250.

18. Mulcahy LA, Pink RC, Carter DR. Routes and mechanisms of extracellular vesicle uptake. J Extracell Vesicles. 2014;3.

19. Taylor DD, Gercel-Taylor C. Exosomes/microvesicles: mediators of cancer-associated immunosuppressive microenvironments. Semin Immunopathol. 2011;33(5):441-54.

20. Thakur BK, Zhang H, Becker A, Matei I, Huang Y, Costa-Silva B, et al. Double-stranded DNA in exosomes: a novel biomarker in cancer detection. Cell research. 2014;24(6):766-9.

21. Li Q, Shao YF, Zhang XJ, Zheng T, Miao M, Qin LJ, et al. Plasma long noncoding RNA protected by exosomes as a potential stable biomarker for gastric cancer. Tumor Biol. 2015;36(3):2007-12.

22. Thind A, Wilson C. Exosomal miRNAs as cancer biomarkers and therapeutic targets. Journal of Extracellular Vesicles. 2016;5.

23. Madhavan B, Yue SJ, Galli U, Rana S, Gross W, Muller M, et al. Combined evaluation of a panel of protein and miRNA serum-exosome biomarkers for pancreatic cancer diagnosis increases sensitivity 
and specificity. Int J Cancer. 2015;136(11):2616-27.

24. Jiang JH, Wu X, Tong XL, Wei WZ, Chen A, Wang XN, et al. GCC2-ALK as a targetable fusion in lung adenocarcinoma and its enduring clinical responses to ALK inhibitors. Lung cancer. 2018;115:5-11.

25. Zheng H, Zhan Y, Liu S, Lu J, Luo J, Feng J, et al. The roles of tumor-derived exosomes in non-small cell lung cancer and their clinical implications. Journal of experimental clinical cancer research: CR. 2018;37(1):226.

26. Kang CW, Han YE, Kim J, Oh JH, Cho YH, Lee EJ. 4-Hydroxybenzaldehyde accelerates acute wound healing through activation of focal adhesion signalling in keratinocytes. Scientific reports. 2017;7(1):14192.

27. Tang Y, Geng Y, Luo J, Shen W, Zhu W, Meng C, et al. Downregulation of ubiquitin inhibits the proliferation and radioresistance of non-small cell lung cancer cells in vitro and in vivo. Scientific reports. 2015;5:9476.

28. Henry CE, Llamosas E, Djordjevic A, Hacker NF, Ford CE. Migration and invasion is inhibited by silencing ROR1 and ROR2 in chemoresistant ovarian cancer. Oncogenesis. 2016;5(5):e226.

29. Shin H, Jeong H, Park J, Hong S, Choi Y. Correlation between Cancerous Exosomes and Protein Markers Based on Surface-Enhanced Raman Spectroscopy (SERS) and Principal Component Analysis (PCA). Acs Sensors. 2018;3(12):2637-43.

30. Shin H, Oh S, Hong S, Kang M, Kang D, Ji YG, et al. Early-Stage Lung Cancer Diagnosis by Deep Learning-Based Spectroscopic Analysis of Circulating Exosomes. ACS Nano. 2020;14(5):5435-44.

31. Park J, Hwang M, Choi B, Jeong H, Jung JH, Kim HK, et al. Exosome Classification by Pattern Analysis of Surface-Enhanced Raman Spectroscopy Data for Lung Cancer Diagnosis. Analytical chemistry. 2017;89(12):6695-701.

32. Kang KW, Jung JH, Hur W, Park J, Shin H, Choi B, et al. The Potential of Exosomes Derived from Chronic Myelogenous Leukaemia Cells as a Biomarker. Anticancer research. 2018;38(7):3935-42.

33. Brown FC, Schindelhaim CH, Pfeffer SR. GCC185 plays independent roles in Golgi structure maintenance and AP-1-mediated vesicle tethering. J Cell Biol. 2011;194(5):779-87.

34. Hurwitz SN, Conlon MM, Rider MA, Brownstein NC, Meckes DG Jr. Nanoparticle analysis sheds budding insights into genetic drivers of extracellular vesicle biogenesis. J Extracell Vesicles. 2016;5:31295.

35. Wolfers J, Lozier A, Raposo G, Regnault A, Thery C, Masurier C, et al. Tumor-derived exosomes are a source of shared tumor rejection antigens for CTL cross-priming. Nature medicine. 2001;7(3):297303.

36. lero M, Valenti R, Huber V, Filipazzi P, Parmiani G, Fais S, et al. Tumour-released exosomes and their implications in cancer immunity. Cell death differentiation. 2008;15(1):80-8.

37. Siegel RL, Miller KD, Jemal A. Cancer statistics. 2015. CA Cancer J Clin. 2015;65(1):5-29.

38. Henschke $\mathrm{Cl}$, International Early Lung Cancer Action Program I. Survival of patients with clinical stage I lung cancer diagnosed by computed tomography screening for lung cancer. Clinical cancer 
research: an official journal of the American Association for Cancer Research. 2007;13(17):4949-50.

39. Scheff RJ, Schneider BJ. Non-small-cell lung cancer: treatment of late stage disease: chemotherapeutics and new frontiers. Semin Interv Radiol. 2013;30(2):191-8.

40. Wang N, Song X, Liu L, Niu L, Wang X, Song X, et al. Circulating exosomes contain protein biomarkers of metastatic non-small-cell lung cancer. Cancer Sci. 2018;109(5):1701-9.

41. Sandfeld-Paulsen B, Aggerholm-Pedersen N, Boek R, Jakobsen KR, Melolgaard P, Folkersen BH, et al. Exosomal proteins as prognostic biomarkers in non-small cell lung cancer. Molecular oncology. 2016;10(10):1595-602.

42. Derby MC, Lieu ZZ, Brown D, Stow JL, Goud B, Gleeson PA. The trans-Golgi network golgin, GCC185, is required for endosome-to-Golgi transport and maintenance of Golgi structure. Traffic. 2007;8(6):758-73.

43. Lin YC, Chiang TC, Liu YT, Tsai YT, Jang LT, Lee FJS. ARL4A acts with GCC185 to modulate Golgi complex organization. Journal of cell science. 2011;124(23):4014-26.

44. Uhlen M, Fagerberg L, Hallstrom BM, Lindskog C, Oksvold P, Mardinoglu A, et al. Proteomics. Tissuebased map of the human proteome. Science. 2015;347(6220):1260419.

\section{Figures}



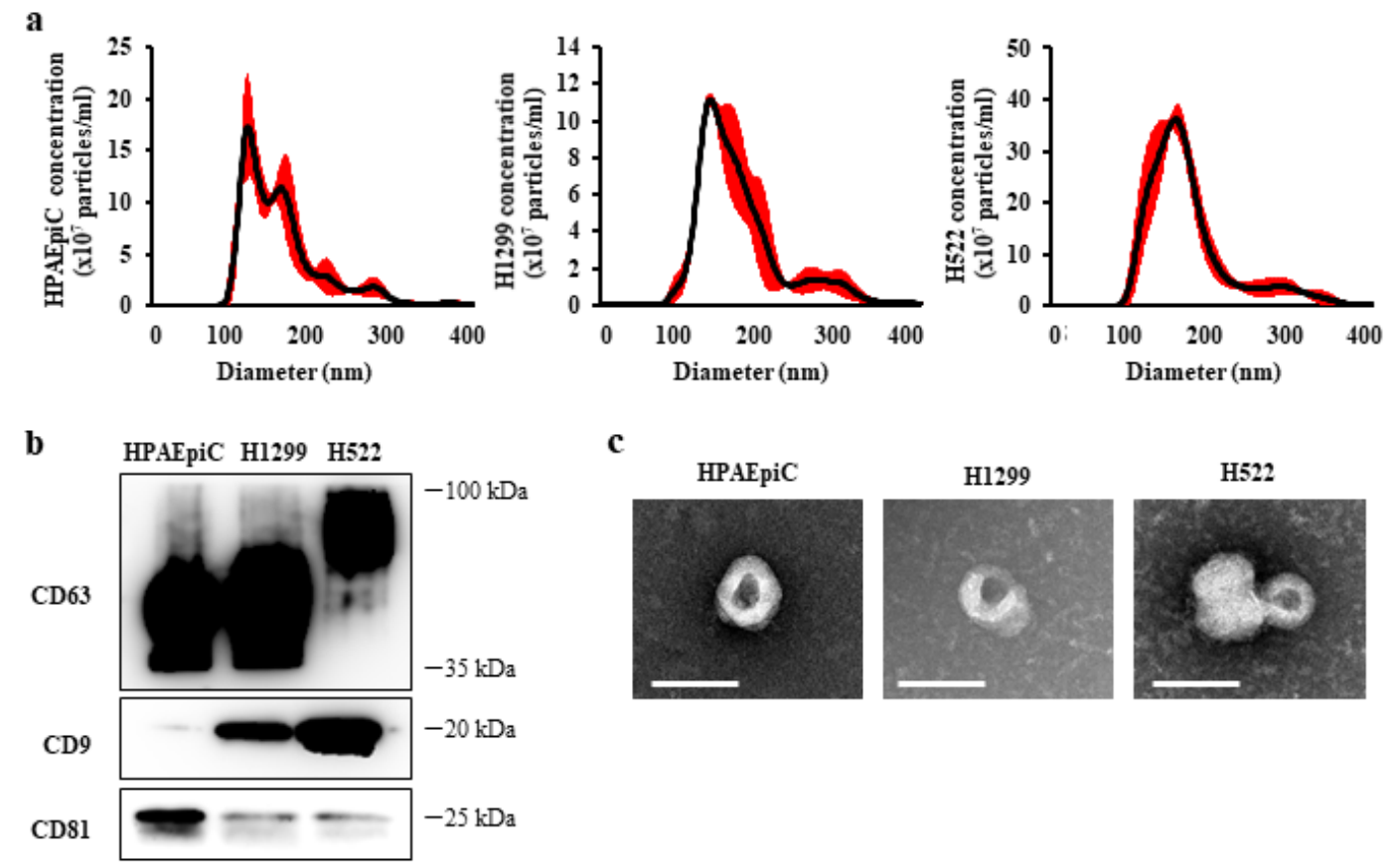

c
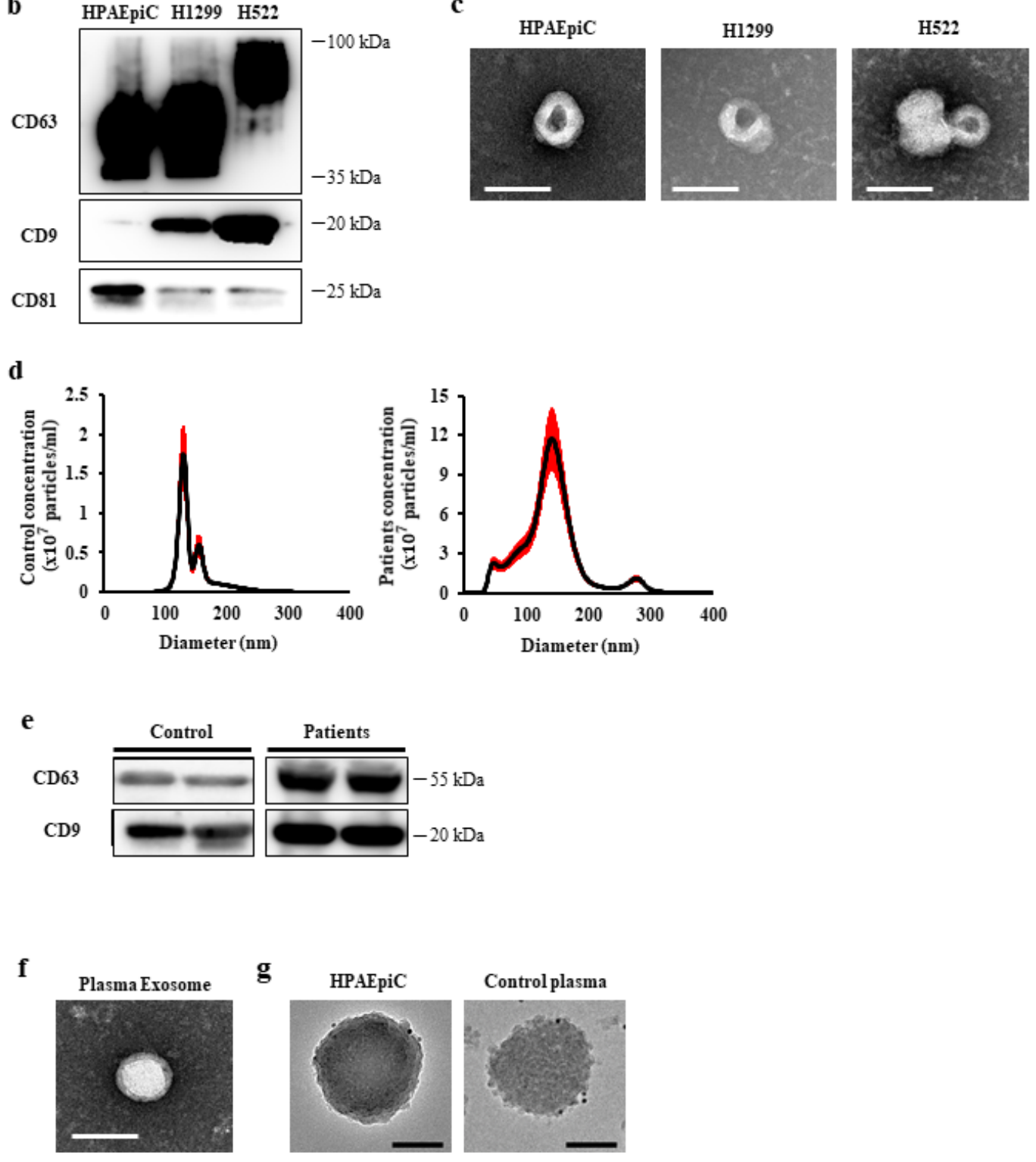

\section{Figure 1}

Characterization of the exosomes released from the normal lung and lung cancer cell lines. (a) Average size of SEC fractions $6-8$ of the exosomes measured by NTA. Each average size is $134.131 \pm 1.99$, $138.73 \pm 6.98$, and $131 \pm 3.2 \mathrm{~nm}$ (mean $\pm \mathrm{SD}$ ). (b) Western blot analysis of the CD63, CD9 and CD81 exosomal proteins in the exosome lysates ( $6 \mu \mathrm{g}$ of total proteins/well of acrylamide gel). (c) TEM analysis shows the typical cup-shape of the exosomes. Scale bar $=100 \mathrm{~nm}$. (d) Average size of SEC 
fractions 6-8 of the exosomes from healthy and patient's plasma measured by NTA. Each average size is $135.36 \pm 5.31$ and $138.71 \pm 12.40$ (mean \pm SD). (e) Western blot analysis of the CD63 and CD9 exosomal proteins in the exosome lysates. (f) TEM analysis shows the typical cup-shape of the exosomes in exosomes derived from plasma. Scale bar $=100 \mathrm{~nm}$. (g) TEM analysis shows immunogold labeling using an anti-CD63 antibody of the exosomes isolated from HPAEpiC and human plasma. Scale bar $=100 \mathrm{~nm}$

$\mathbf{a}$

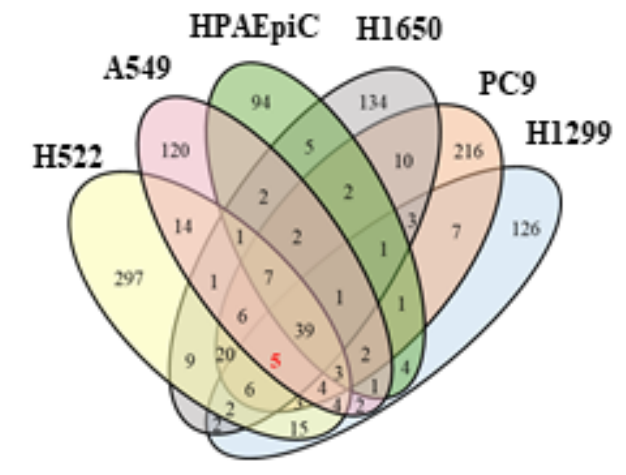

\section{Cellular Component}

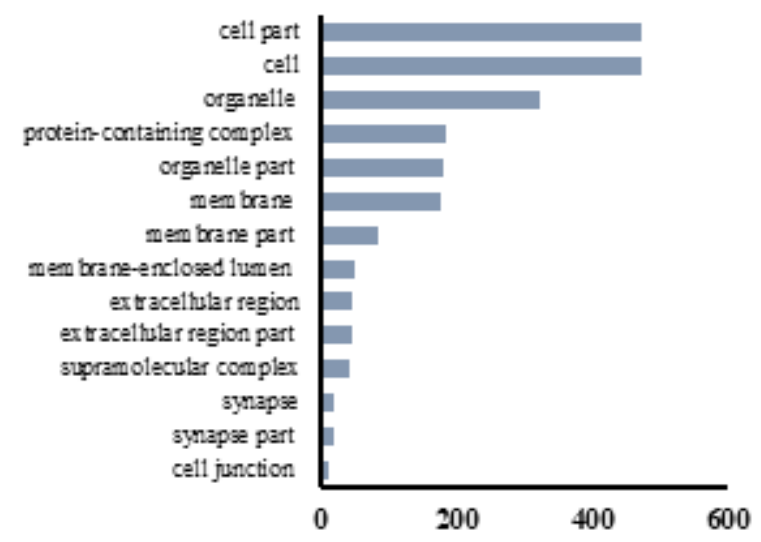

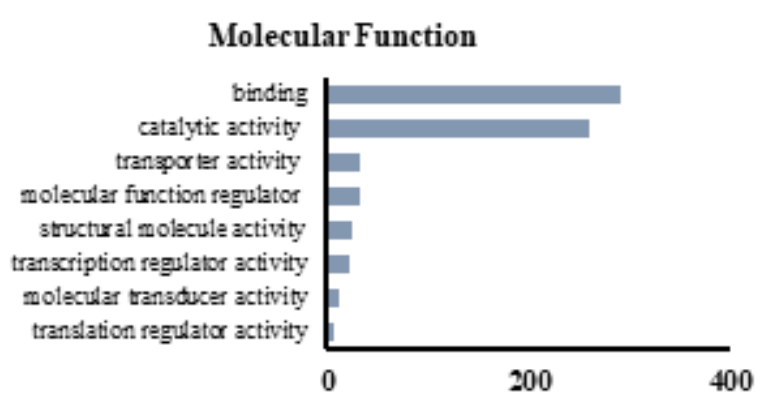

Biological Process

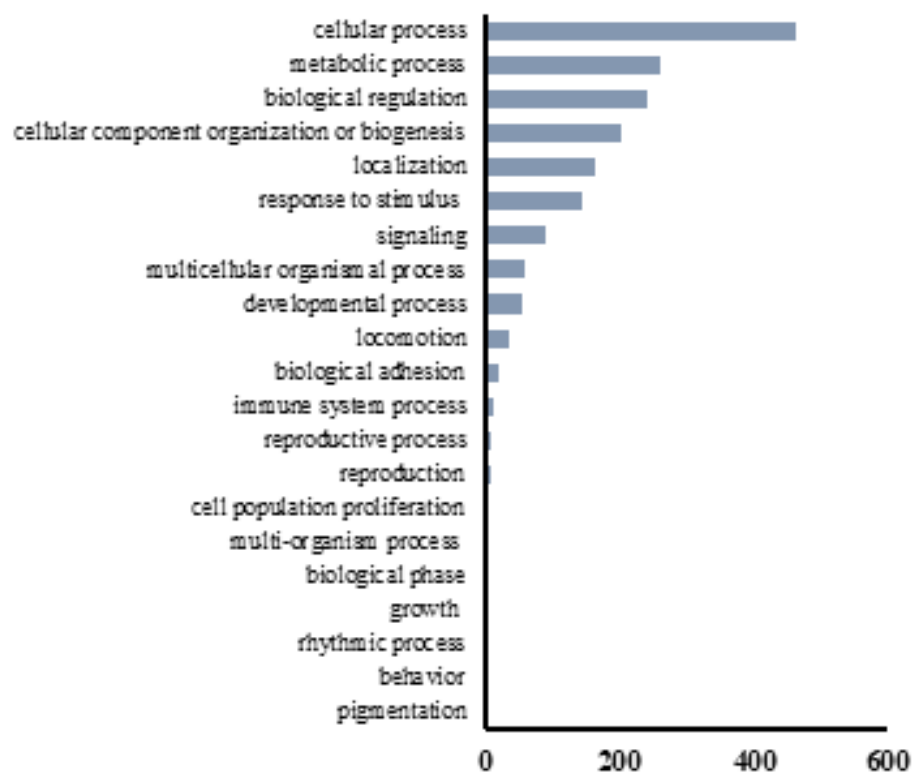

b

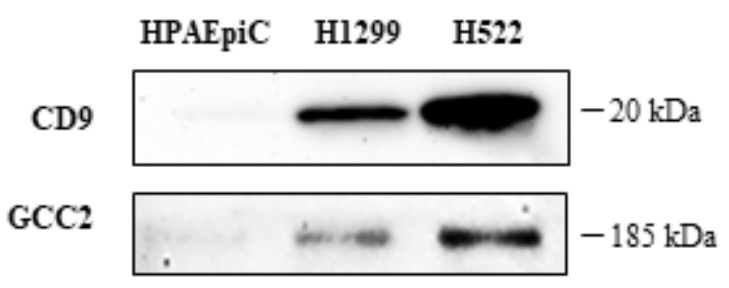

c

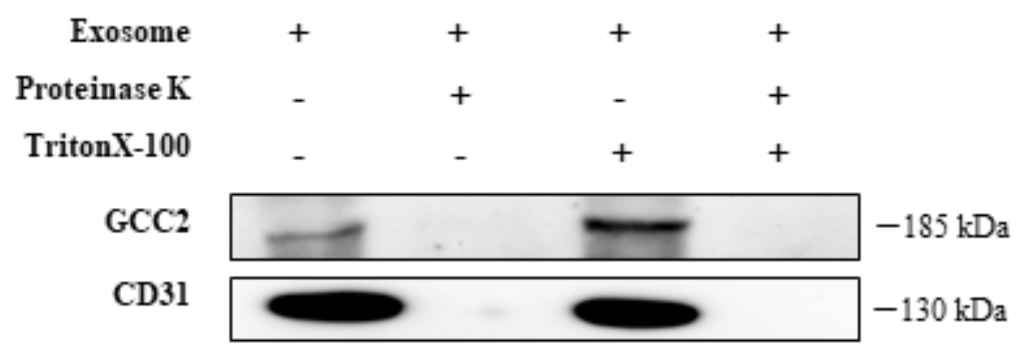

Figure 2 
Identification of a potential factor for NSCLC diagnosis and treatment by proteomic analysis. (a) A Venn diagram for the proteomic analysis and Gene Ontology classification of the exosomes derived from six cell lines. (b) GCC2 expression in the exosome lysates by western blot. (c) GCC2 protein present on both the surface and inside the exosomes. The GCC2 protein disappeared following exposure of the surface proteins of the exosomes to proteinase $\mathrm{K}$.
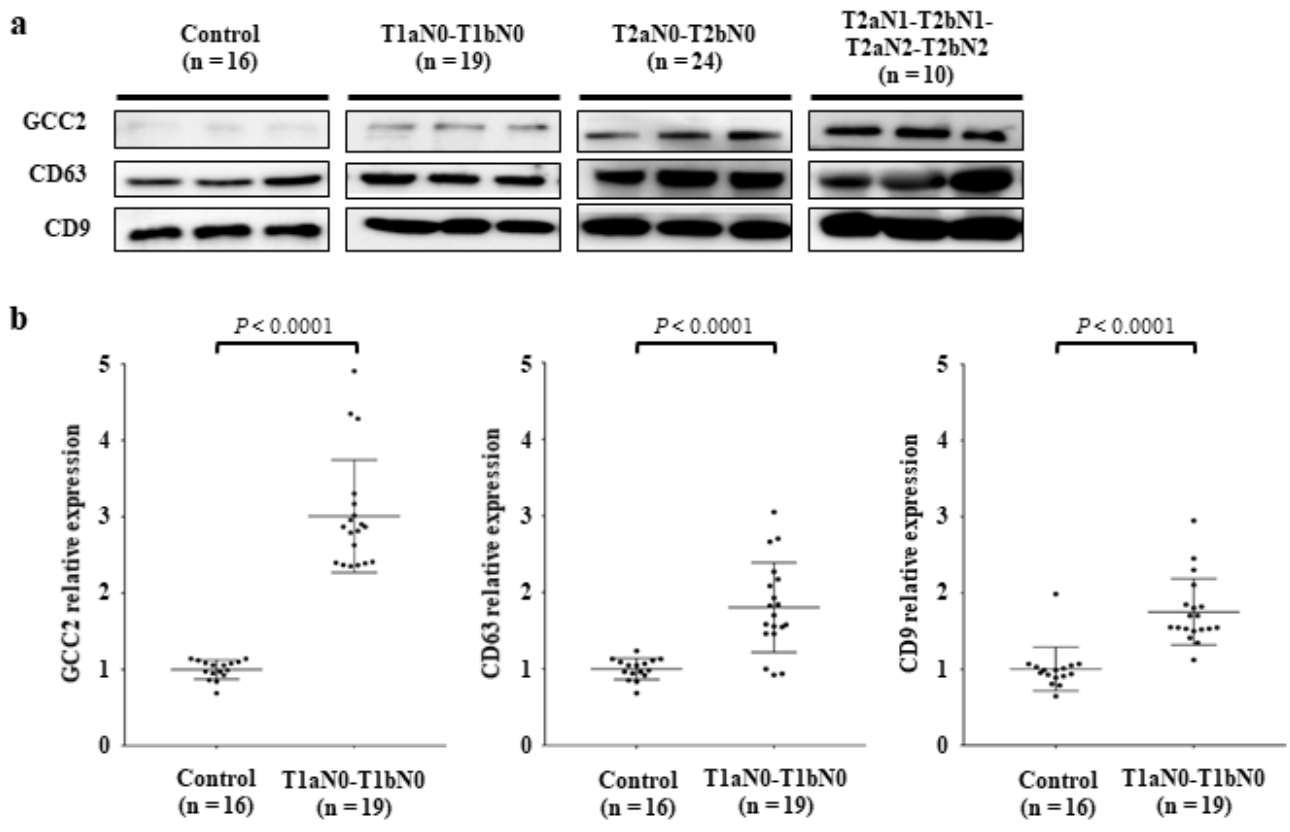

c
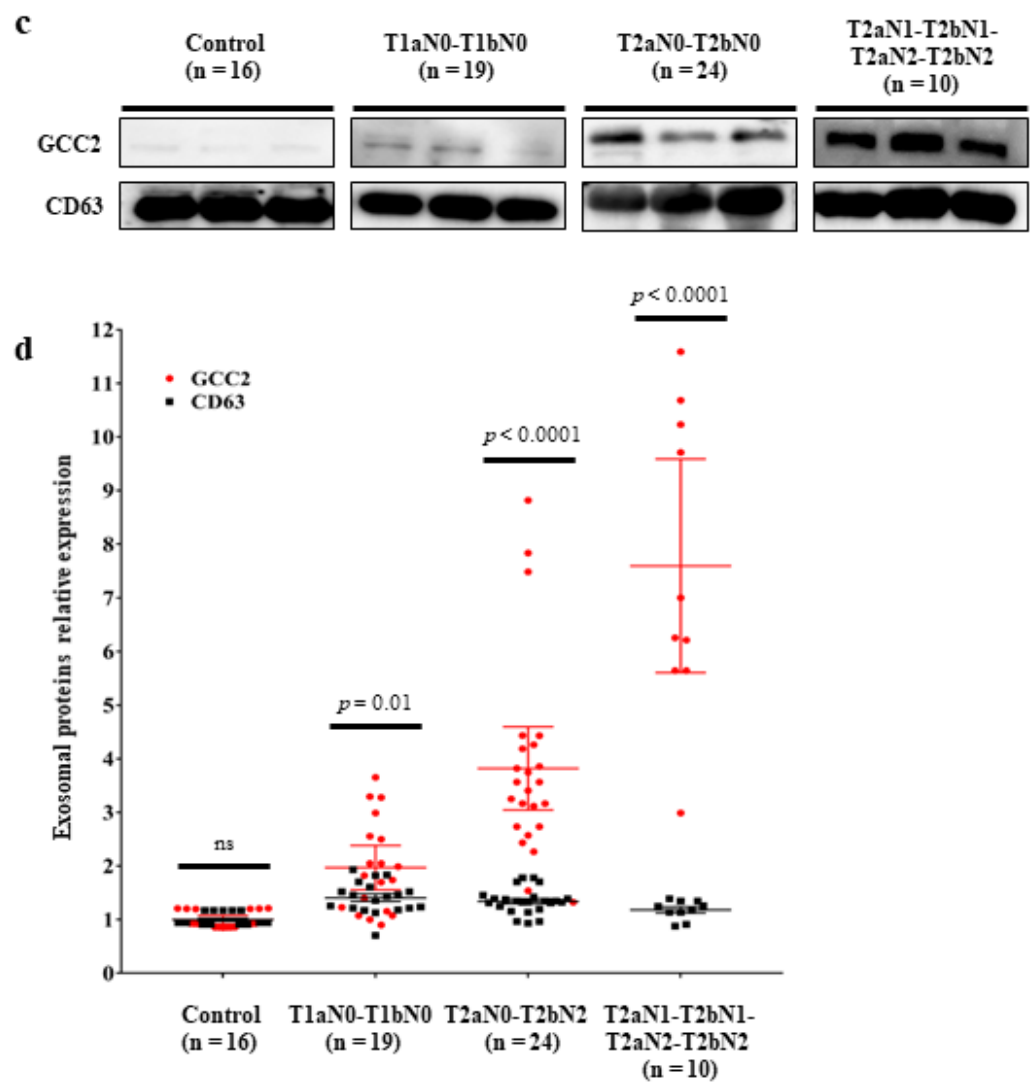

Figure 3 
Expression levels of GCC2 in the exosomes derived from plasma of patients with NSCLC. (a) Comparison of $\mathrm{GCC} 2, \mathrm{CD} 63$, and $\mathrm{CD} 9$ protein expression in the plasma-derived exosomes isolated from the group of healthy controls $(n=16)$ and patients with different pathological stages of NSCLC $(n=53)$ by western blot analysis. Each of three lanes represents 3 healthy controls and 3 patients with NSCLC at different pathological stages. (b) Comparison of the relative intensities of $\mathrm{GCC} 2, \mathrm{CD} 63$, and $\mathrm{CD} 9$ protein expression between the control group and T1aN0-T1bN0 patient group $(n=19)$. The protein intensities were measured by ImageJ. An independent Student's t-test and the Jonckheere-Terpstra test were used for statistical validation. (c) Comparison of the expression levels of GCC2 and CD63 proteins in the plasma-derived exosomes isolated from the group of normal healthy controls and the patients with different pathological stages of NSCLC by western blotting. The same exosome number measured by NTA was used for western blotting. Each of three lanes represents 3 healthy controls and 3 patients with NSCLC at different pathological stages. (d) Comparison of the relative intensities of GCC2 and CD63 protein expression levels. The GCC2 expression levels but not CD63 expression levels gradually increased as the pathological stages progressed.

a

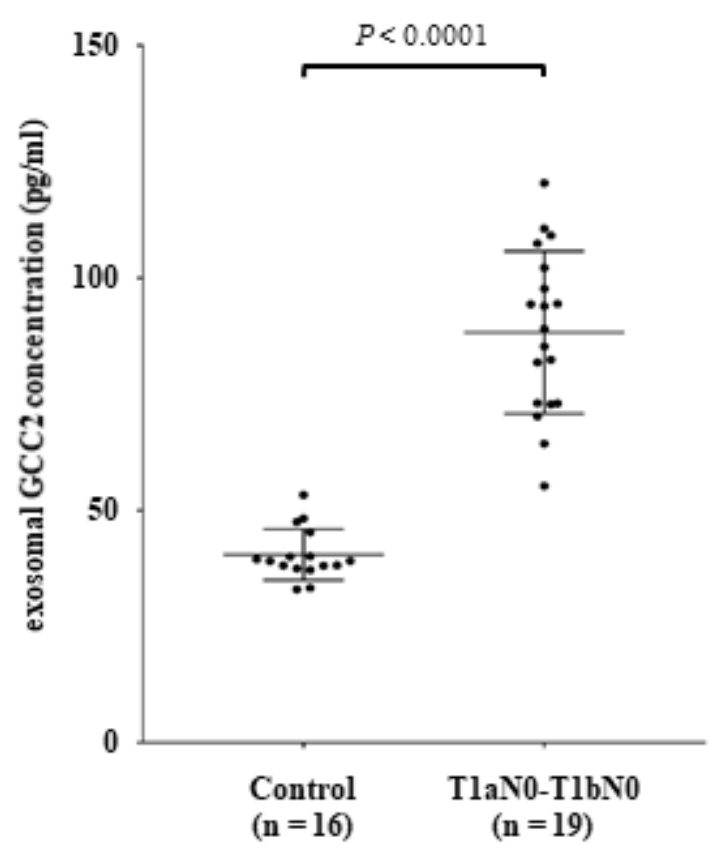

b

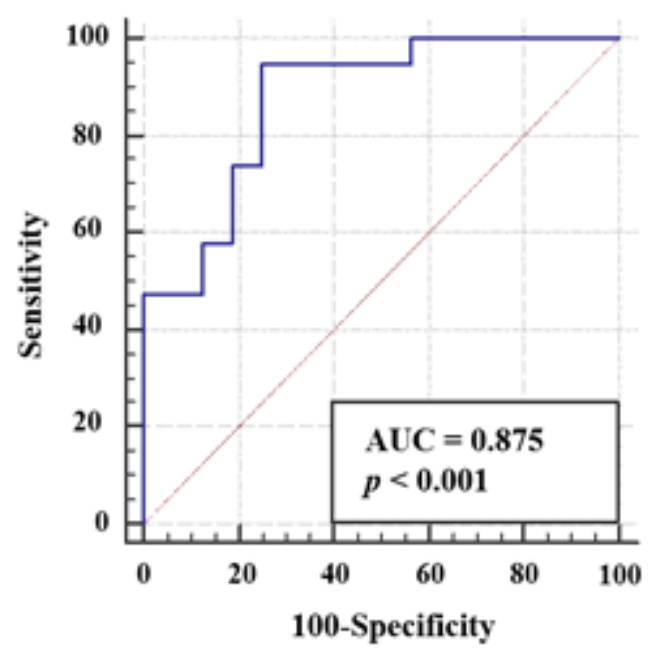

AUC: $0.875(p<0.001)$

Sensitivity: 94.74

Specificity : 75.00

cut-off : 12.30

\section{Figure 4}

Evaluation of the exosomal GCC2 protein as a diagnostic biomarker for patients with early lung cancer. (a) Concentration of the exosomal GCC2 protein in the group of healthy controls ( $n=16)$ and patients with T1aNO-T1bNO lung cancer $(n=19)$ by an ELISA assay. (b) Receiver operating characteristic (ROC) curve based on the expression levels of the exosomal GCC2 protein, distinguishing the patients with early 
NSCLC from the normal healthy controls. An independent Student's t-test and the Jonckheere-Terpstra test were used for statistical validation.
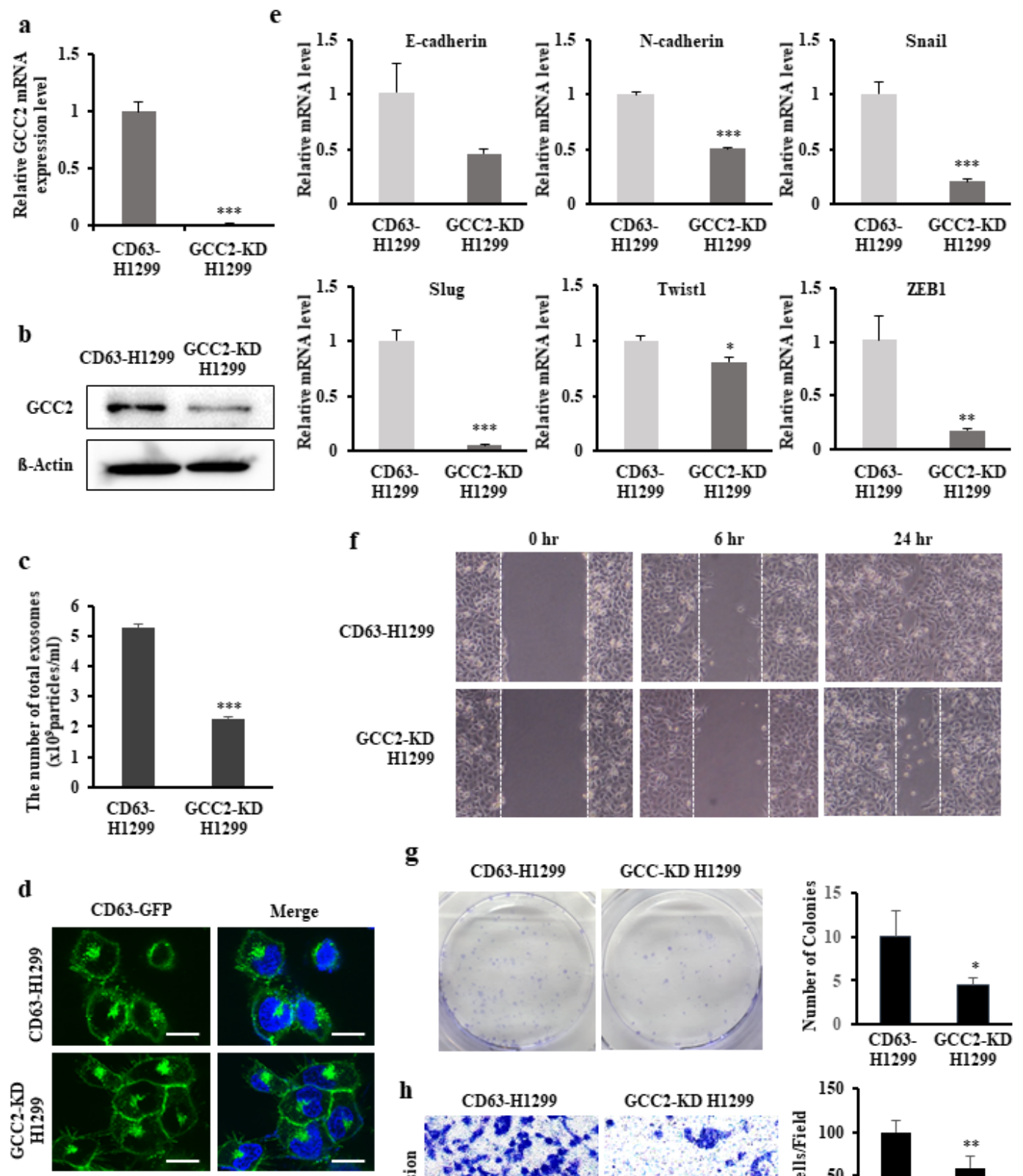

g
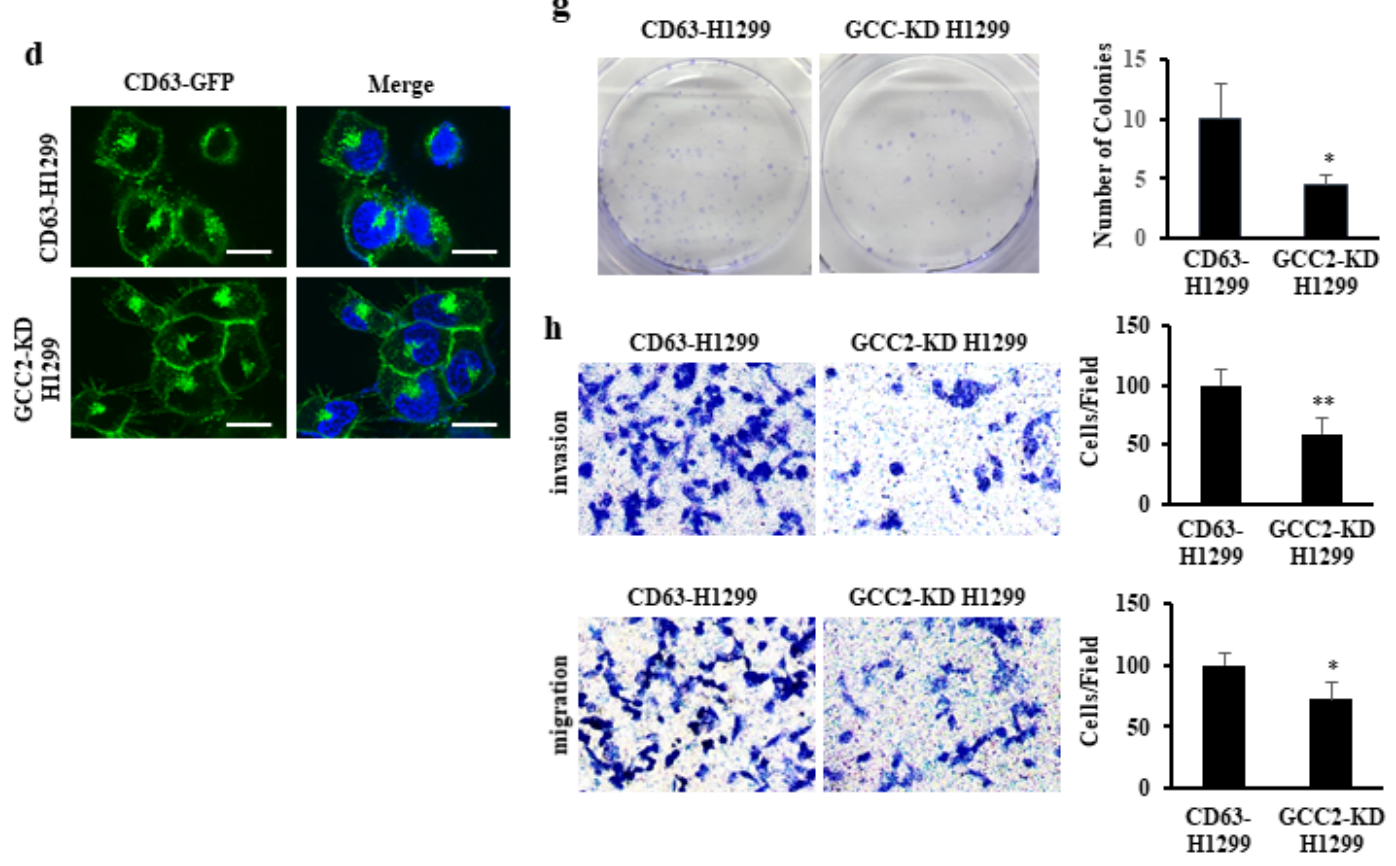

Figure 5

Effects of exosomal GCC2 protein on cell behavior properties as a therapeutic target by its knockdown in the cancer cell lines. $(a, b)$ Expression levels of GCC2 mRNA and protein in the cancer cell line H1299 treated with GCC2 shRNA (GCC2-KD H1299). (c) The number of the exosomes in GCC2-KD H1299, as 
counted by NTA. (d) The morphological alterations in GCC2-KD H1299. (e) Expression levels of the MET genes in GCC2-KD H12299. (f) Inhibition of cellular motility in GCC2-KD H1299 by a wound-healing assay. (g) Inhibition of colony formation in GCC2-KD H1299. Representative images of biological triplicates and the quantitative analysis of colony numbers. (h) Inhibition of cell migration and invasion in GCC2-KD $\mathrm{H} 12299$. The average migrated/invaded cells were counted in random fields. Data represented as mean \pm SD of independent experiments of at least triplicate biological replicates. ${ }^{\star} p<0.05,{ }^{\star \star} p<0.01,{ }^{\star \star \star} p<$ 0.001 .

\section{Supplementary Files}

This is a list of supplementary files associated with this preprint. Click to download.

- supplefigure.docx

- Supplementarytable1.PrimersequenceGCC2.docx

- Supplementarytable2.Proetomicanalysis.xlsx

- supplementarytable3.sizeofexosomes.docx 